\title{
Analysis/Spectrum of admitted cases of lower extremity arterial disease (LEAD) in University Hospital of Nepal.
}

\author{
Robin Man karmacharya ${ }^{1}$, Satish Vaidya ${ }^{1}$, Amit Kumar Singh ${ }^{1}$, Prasesh Dhakal ${ }^{1}$, Sushil Dahal ${ }^{1}$, Prabha \\ Shrestha ${ }^{1}$, Sohail Bade ${ }^{1}$, Niroj Bhandari ${ }^{1}$ \\ ${ }^{1}$ Department of Surgery (Cardio Thoracic and Vascular), Dhulikhel Hospital, Kathmandu University Hospital, Dhulikhel, Nepal
}

\section{CORRESPONDENCE}

\author{
Dr. Robin Man Karmacharya, \\ Cardio Thoracic and Vascular Unit, \\ Kathmandu University Hospital, \\ Dhulikhel, Nepal \\ Email-reachrobin773@hotmail.com
}

\section{ARTICLE INFO}

\section{Article History}

Submitted: 25 December 2020

Accepted: 19 January, 2021

Published: 8 February,2021

Source of support: None

Conflict of Interest: None

Copyright : CThe Author(S) 2020 This is an open access article under the Creative Common Attribution license CC-BY 4.0

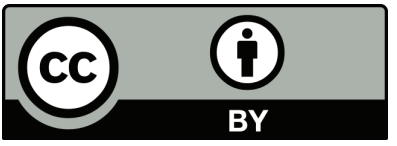

\begin{abstract}
Introduction: Peripheral arterial disease is a condition due to partial or complete occlusion of arteries excluding that of heart and brain. Lower extremity arterial disease is specific to lower limbs. Some of the patients are asymptomatic while a majority present with claudication, rest pain, ulceration or even gangrene.
\end{abstract}

\begin{abstract}
Methods: We took all admitted cases of lower extremity arterial disease from January, 2015 to December 2018. ABI was used as the first clinical tool for the diagnosis of PAD in patients with history or physical examination findings suggestive of PAD as per AHA guidelines. Outpatient arterial Doppler ultrasonography complemented by lower limb CT angiogram was used as a confirmatory tool for the diagnosis and also to assess anatomical location and severity of stenosis.
\end{abstract}

Results: Total of 54 cases of lower extremity arterial diseases were identified with a mean age of 59.2 years (S.D. 11.4). Right lower limb was involved in 35(50\%). Mean age was 58 years(SD 13.1). Mean duration of symptom was 3.4 years (SD 3.3). Claudication was present in all the patients. $32(45.7 \%)$ had ulcers. Toe(44.3\%) was most commonly involved. Decreased local temperature(91.4\%) and color change(87.1\%) were major symptoms. $35(50 \%)$ of the patients had gangrene. Mean peak systolic velocity was lowest in the peroneal artery. $16.6 \%$ patients got additional peripheral bypass surgery.

Conclusion: Claudication, decreased local temperature and color change were very common findings of lower extremity arterial disease. Gangrene was present in half of the patients.

Keywords: Lower extremity arterial disease; Peripheral arterial disease; Ulceration.

\section{INTRODUCTION}

Peripheral Arterial Disease (PAD) is a condition where there is partial or complete occlusion of arteries, excluding arteries of the brain and heart. PAD is usually part of severe systemic atherosclerosis causing high morbidity and mortality. ${ }^{1}$ Lower extremity arterial disease(LEAD) is specific to PAD in lower extremities and can be asymptomatic or presents with claudication, pain at rest, skin ulceration to critical limb threatening ischemia and gangrene. ${ }^{2-5}$ Knowing the appropriate stage and subjecting the patients for appropriate treatment is essential for best outcome in this condition. Commonly used classification systems to qualify the level of PAD are the Fontaine and Rutherford-Becker grading system and Wifi classification which predicts patients who are at risk of amputation. . $^{6,7} 8$ Non invasive diagnostic modalities like measurement of Ankle Brachial Index (ABI), Doppler ultrasonography, CT angiogram are recommended to diagnose PAD and also know the spectrum of PAD. ${ }^{9}$ For medical management, patient are usually prescribed with statins like Atorvastatin, antiplatelet agent like Aspirin and Cilastazole. ${ }^{10,11}$ Major Adverse Limb Events (MALE) in LEAD was found to be $2 \%$ in one major trial. ${ }^{12}$ MALE includes acute or chronic limb ischemia leading to major vascular amputations.

There is scarcity of studies on PAD in Nepal. Prevalence of PAD in patients undergoing dialysis has been studied which was $30 \%{ }^{13}$ Another study showed the prevalence of PAD as $18.5 \%$ in more than 40 years personnel visiting out patient department. ${ }^{14}$ In a study done at India, prevalence of PAD was $26.7 \%$ in more than 60 years population. ${ }^{15}$ Thereareonlyfewcentersin Nepaladdressing LEADincluding operative management. Analysis of LEAD at a University Hospital with a vascular surgical team will unravel the true spectrum of this disease. This study is done to know 
different parameters such as history, examination finding, imaging finding and outcome of admitted cases of LEAD at University hospital from 2015 January to 2018 December.

\section{METHODS}

This was a descriptive study including all the patients admitted in Dhulikhel Hospital with the diagnosis of LEAD in the year January 2015 to December 2018. Data was obtained through the hospital records of the patients. Detail records were collected on the variables such as age, sex, major complaints, duration of the symptoms, site of the lesion, smoking status, history of amputation, further management performed etc were recorded. Confirmation of LEAD is done by outpatient arterial Doppler ultrasonography and also complemented by lower limb CT angiogram. ${ }^{16}$

In this study, $A B I$ was used as a first clinical tool for the diagnosis of PAD in patients with history or physical examination findings suggestive of PAD as per AHA guidelines. Outpatient arterial Doppler ultrasonography complemented by lower limb CT angiogram was used as a confirmatory tool for the diagnosis and also to assess anatomical location and severity of stenosis for patients in whom revascularization was planned. $A B I$ is also indicated as first-line noninvasive test for screening and diagnosis of LEAD by ESC. ${ }^{17}$ The American Diabetes Association Consensus Statement recommends that a screening ankle-brachial index (ABI) should be performed in diabetes patients with symptoms or signs of PAD. ${ }^{18,19}$

Regarding Doppler ultrasonography, flow type, peak systolic velocity was obtained in standard technique at femoral artery, popliteal artery, Anterior Tibial Artery and Posterior Tibial Artery. Note on the medical management and surgical treatment was also done. ABI can be measured manually, using Doppler Ultrasonography or using an automated oscillometric device. ${ }^{20-21}$ We used Doppler Ultrasonography for assessment of Blood pressure for calculation of $\mathrm{ABI}$. For doppler ultrasonography Acuson P300 machine by Siemens was used with linear probe of 7.5-10MHz using appropriate gain and depth.

The normal peripheral arterial waveform is triphasic, the first positive deflection is forward systolic flow, the negative deflection or dip is the diastolic reversed flow and the third small positive deflection is late diastolic forward flow due to wall recoil, it correlates with wall elasticity. The normal peak systolic velocity (PSV) in peripheral lower limb arteries varies from $45-180 \mathrm{~cm} / \mathrm{s}$ whereas severe arterial disease manifests as a PSV in excess of $200 \mathrm{~cm} / \mathrm{s}$, monophasic waveform and spectral broadening of the Doppler waveform. ${ }^{22}$ Doppler signal is acquired at an angle of 60 degrees or as small as possible, and velocity spectra are recorded proximal to and at the site of maximum flow disturbance. ${ }^{23}$

Collected data were analysed using SPSS 13. For sample size calculation we used $2 \%$ prevalence of Major Adverse Limb Event. Hence $p=0.02, q=0.98$, Sample size= $4 * 0.02 * 0.98 /(0.05)^{\wedge} 2=31$. Descriptive statistics was used to calculate demographic information, presence of risk factors, health history and presence of various symptoms among the participants and were presented in frequency and percentage. Scalar variables will be expressed as mean, standard deviation and range.

\section{RESULTS}

Total of 54 cases of lower extremity arterial diseases were identified during the study period. Mean age of the patient was 59.2 years (S.D. 11.4 , Range $28-81$ years). Right lower limb was involved in 35 (\%) while left was involved in 35 (\%). Of these 70 limbs, bilateral involvement was present in 16 patients (\%). For ease in data analysis and presentation, further analysis is done in 70 limbs. Mean age was 58 years (SD 13.1, Range 36- 81 years). Mean duration of symptom was 3.4 years (SD 3.3, Range 1-15 years). Male:Female ratio was 6:1. Claudication was present in all the patients. Mean claudication distance was 162.8 meters (SD 185.8, Range 0-500meters). In 34 patients (48.6\%) rest pain was present. In 32 patients (45.7\%) ulceration was present. Table 1 shows location of most proximal ulceration. Most common ulceration was present in toes followed by feet.

\section{Table 1: Location of most proximal ulceration}

\begin{tabular}{lll} 
Location of ulcer & Number & Percentage \\
Toes & 21 & 30 \\
\hline Feet & 8 & 11.4 \\
Calf & 3 & 4.3 \\
\hline Total & 32 & 45.7
\end{tabular}

In terms of history of amputation due to peripheral arterial disease, in 20 patients (28.6\%) there was history of amputation. Most common amputation was in toes (12 patients, 17.1\%) followed by feet in 8 patients (11.5\%). Mean duration since amputation was 4 months (SD: 3 months, Range 1month - 1 year). None of the patient developed morbidities like myocardial infarction, cerebrovascular event during the admission.

Regarding smoking status, 64 patients (91.4\%) were smoker. Of the smoker patients, mean pack years was 
27.2 (SD 11.6, Range 6-49). All the cases where there was a history of amputation were smoker. In terms of most distal involved area, most common location was toes (44.3\%) followed by feet $(27.1 \%)$, calf $(18.6 \%)$ and ankle $(10 \%)$. In terms of major risk factors, diabetes was present in 31 patients (44.3\%), hypertension in 26 patients (37.1\%), dyslipidemia in 37 patients (52.9\%) and family history of peripheral arterial disease in 3 patients (4.3\%).

In terms of major symptoms, decreased temperature was present in 64 patients $(91.4 \%)$, color change was present in 61 patients $(87.1 \%)$, sensory loss was present in 3 patients $(4.3 \%)$, motor loss was not present in any cases (not taking consideration of distal muscles in amputation cases), atrophic signs in calf was present in 13 patients (18.6\%), gangrene was present in 35 patients (50\%). Coexisting upperlimb involvement was present in 3 patients (4.3\%). Table 2 shows status of pulse in lower limb. In femoral artery pulse was palpable in $92.9 \%$ of cases. This however decreased to $57.1 \%$ palpable pulse in popliteal artery. Pulse in popliteal artery was feeble in $24.3 \%$. In crural vessels, posterior tibial artery was palpable more compared to anterior tibial.

\begin{tabular}{|c|c|c|c|c|}
\hline & Location & Pulse & Number & Percentage \\
\hline \multirow[t]{3}{*}{1} & \multirow[t]{3}{*}{ Femoral } & Palpable & 65 & 92.9 \\
\hline & & Feeble & 0 & 0 \\
\hline & & $\begin{array}{l}\text { Not } \\
\text { palpable }\end{array}$ & 5 & 7.1 \\
\hline \multirow[t]{3}{*}{2} & \multirow[t]{3}{*}{ Popliteal } & Palpable & 40 & 57.1 \\
\hline & & Feeble & 17 & 24.3 \\
\hline & & $\begin{array}{l}\text { Not } \\
\text { palpable }\end{array}$ & 13 & 18.6 \\
\hline \multirow[t]{3}{*}{3} & \multirow{3}{*}{$\begin{array}{l}\text { Anterior } \\
\text { Tibial }\end{array}$} & Palpable & 5 & 7.1 \\
\hline & & Feeble & 5 & 7.1 \\
\hline & & $\begin{array}{l}\text { Not } \\
\text { palpable }\end{array}$ & 60 & 85.7 \\
\hline \multirow[t]{3}{*}{4} & \multirow{3}{*}{$\begin{array}{l}\text { Posterior } \\
\text { Tibial }\end{array}$} & Palpable & 11 & 15.7 \\
\hline & & Feeble & 16 & 22.9 \\
\hline & & $\begin{array}{l}\text { Not } \\
\text { palpable }\end{array}$ & 43 & 61.4 \\
\hline \multirow[t]{3}{*}{5} & \multirow{3}{*}{$\begin{array}{l}\text { Dorsalis } \\
\text { Pedis }\end{array}$} & Palpable & 2 & 2.9 \\
\hline & & Feeble & 0 & 0 \\
\hline & & $\begin{array}{l}\text { Not } \\
\text { Palpable }\end{array}$ & 68 & 97.1 \\
\hline
\end{tabular}

Table 3 shows percentage of different waveform in different arteries along with mean peak systolic velocity. Maximum percentage of no flow was noted in peroneal artery and the mean peak systolic velocity is also minimum in peroneal artery. Maximum percentage of triphasic waveform was noted in femoral artery and the mean peak systolic velocity was also highest in femoral artery. Regarding $\mathrm{ABI}$ measurement, mean $\mathrm{ABI}$ was 0.37 (S.D. 0.28, Minimum 0, Maximum 0.80). There were 30 patients (42.9\%) with $A B I$ less than 0.5 and 40 patients with $\mathrm{ABI}$ more than or equal to 0.5 (57.1\%).

In terms of surgical management, 9 patients (16.6\%) underwent peripheral bypass surgery. Of them, two underwent femorofemoral bypass, two underwent patch plasty in femoral artery, three underwent femoropopliteal bypass, two underwent femoro-crural bypass. Of these cases, 8 patients had bypass patency during followup of more than six months. In one patient (femoro crural bypass) there was long segment thrombosis with bypass failure during followup at two weeks but patient had some clinical improvement and did not opt for re-intervention.

\section{DISCUSSION}

We analyzed the cases of lower extremity arterial disease presenting at our hospital. A study found prevalence of peripheral arterial disease in India to be $26.7 \%$ in age group 60-79 years and similar prevalence is expected to be in Nepal. ${ }^{15}$ In a study done in the USA, the prevalence of PAD in more than 65 years age group was $20 \%{ }^{24}$ However, a review article comparing prevalence of PAD in South Asia with that in Western countries, pointed to significantly lower prevalence in South Asia. ${ }^{25}$ Mean age in our series was 59.2 years. In another study done in the USA, the mean age in men was 69 years and that in women was 72 years. ${ }^{26}$

In one major trial to find Major Adverse Limb Event (MALE) in LEAD cases male:female ratio was 2.6:1. ${ }^{12}$ We had even higher male:female ratio (6:1) probably due to higher health seeking behaviour in male patients in our context. Generally, $10 \%$ of patients with PAD experience intermittent claudication, $50 \%$ of patients experience a spectrum of symptoms other than intermittent claudication and $40 \%$ are asymptomatic. ${ }^{27}$ In the Edinburgh Artery Study, the prevalence of asymptomatic PAD in the general population was $8 \%$ which is still a large fraction of the population which hence emphasizes the need of reliance on signs of PAD rather than symptoms for its diagnosis. ${ }^{28}$ In our study, 34 patients (48.6\%) experienced rest pain.

Smoking, hypertension, hyperlipidemia, physical inactivity, obesity and diabetes are the major modifiable risk factors for peripheral arterial disease. ${ }^{10,29,30}$ Our study shows much coherent findings where, the major risk factors 
present were smoking (91.4\%), dyslipidemia (52.9\%), diabetes (44.3\%), hypertension (37.1\%), and family history of peripheral arterial disease (4.3\%). Examination for PAD mainly focuses on palpation of pulses in lower extremities and finding any audible bruits on auscultation. Signs of any dependent rubor and elevation pallor may suggest an advanced stage of PAD. Some other common signs for PAD may be arterial ulceration, shiny skin, muscular atrophy and hair loss. ${ }^{27}$ The PARTNERS program had found that $50 \%$ of cases of peripheral arterial disease may have a normal peripheral pulse. ${ }^{31}$

In this study, the mean ABI was 0.37 (S.D. 0.28 , Minimum 0 , Maximum 0.80$)$. There were 30 patients $(42.9 \%)$ with $A B I$ less than 0.5 and 40 patients with $A B I$ more than or equal to 0.5 (57.1\%). If measured among patients seen in routine clinical practice or the population in general, the specificity of the $A B I$ was in the $97 \%$ range, but the sensitivity was lower, closer to $80 \%$ in part due to some patients with PAD with stiff ankle arteries and falsenegative $A B I s .{ }^{29} \mathrm{~A}$ study from Sri Lanka found that at the level of $A B P I \leq 0.85$ the sensitivity of detecting PAD was $82.6 \%$ and specificity was $100 \%$. ABPI $\leq 0.89$ was observed as the best cutoff value to identify those with PAD. ${ }^{32}$ $A B P I \leq 0.9$ is the cutoff value recommended by ACC/AHA guidelines to diagnose PAD. [33]The clinical utility of ankle-brachial index (ABI) is not clear in subjects with less severe or calcified vessel. ${ }^{34}$ Although the gold standard is Catheter angiography for diagnosis of PAD, another tool in our arsenal is Color Doppler Ultrasonography. Doppler spectral analysis can determine the highest PSV (PSV at the lesion) as well as the PSV in the area adjacent to the normal-looking segment (PSV proximal). ${ }^{23}$ PSV was found to correlate with stenosis as evident on angiographic measurement. 35,36

In a study by Kyu Yeon Hur et. al. among 324 Type II Diabetes Mellitus patients, 18 (5.6\%) had an abnormally low ABI $(\leq 0.90)$ and the other 306 (94.4\%) had ABI 0.91 to 1.40. However, color Doppler ultrasonography demonstrated that $93(28.7 \%)$ had PAD and among them only $16(17.2 \%)$ had an abnormally low $\mathrm{ABI}$, and 77 (82.8\%) had $\mathrm{ABI} 0.91$ to 1.40 . Among the 306 patients with $A B I 0.91$ to $1.40,34$ (11.1\%) had grade III ( $50 \%$ to $99 \%$ stenosis) lesions, and $43(14.1 \%)$ had grade IV (100\% stenosis) lesions on color Doppler ultrasonography. These results suggest that the $A B I$ has the potential to underestimate the presence of PAD. ${ }^{34}$ In this study, the maximum percentage of triphasic waveform was noted in femoral artery and the mean peak systolic velocity was also highest in femoral artery. Mean $\mathrm{ABI}$ was 0.37 (S.D. 0.28, Minimum 0, Maximum 0.80). There were 30 patients (42.9\%) with $\mathrm{ABI}$ less than 0.5 and
40 patients with $A B I$ more than or equal to 0.5 (57.1\%). In another study, Peak systolic velocities (PSV) were recorded as falling into one of the following four ranges: absent flow, $<180 \mathrm{~cm} / \mathrm{s}, 180$ to $249 \mathrm{~cm} / \mathrm{s}$, or $250 \mathrm{~cm} / \mathrm{s}$ or greater. Percent stenosis was calculated using North American Symptomatic Carotid Endarterectomy Trial (NASCET) criteria and recorded in four ranges: completely occluded, 0 to $39.9 \%, 40$ to $69.9 \%$, or 70 to $99.9 \%$. DUS and angiograms were considered to be in agreement if PSV and stenosis ranges correlated (absent flow and complete occlusion, $<180 \mathrm{~cm} / \mathrm{s}$ and 0 to $39.9 \%, 180$ to $249 \mathrm{~cm} / \mathrm{s}$ and 40 to $69.9 \%, \geq 250 \mathrm{~cm} / \mathrm{s}$ and $\geq 70$ to $99.9 \%$ ).DUS was found to demonstrate a sensitivity of $79.7 \%$, specificity of $79.2 \%$, positive predictive value of $88.2 \%$, and negative predictive value of $66.7 \%$ for lesions $\geq 70 \%$. The $66.7 \%$ of the false-negative lesions with the lowest velocities were below the knee joint. ${ }^{37}$ Lower extremity ulcers is among the common complication of peripheral arterial disease, accounting for about 10 to $30 \%$ of all leg ulcers. The ulcers are typically painful and can be present on toes, pressure points such as the heel, malleoli or the anterior shin. ${ }^{38}$

A study by Kobayashi et al in 177 individuals found wound location most commonly at toe followed by Heel. ${ }^{39,40}$ Heel and extensive wounds were found difficult to heal. ${ }^{39,40}$ Further, delayed heel ulcer are directly linked to major amputation. ${ }^{39}$ Our study showed ulceration most commonly in toe followed by feet. According to one population based study, the incidence of amputation in PAD accounts for about $2 \%$ per year. ${ }^{41}$ The rate of amputation also depends upon disease severity with higher risk at initial hospitalization $(3.1 \%, 26.7 \%$, and $55.0 \%$ for Rutherford 4,5 , and 6 , respectively) and also with long term follow up with $(12.1 \%, 35.3 \%$, and $67.3 \%$ for Rutherford 4, 5, and 6, respectively). Presence of comorbid condition also affects the outcome with diabetes as a major risk factor with higher amputation rate. ${ }^{42}$ The SVS WIfI classification is another tools that uses three major categories: wound, ischemia, and foot infection to stratifies risk of wound healing, amputation and likely benefit from revascularization. ${ }^{8}$ In our study, 20 patients $(28.6 \%)$ underwent amputation.

\section{CONCLUSION}

Lower extremity arterial disease is a common vascular condition that might need admission followed by medical and surgical treatment. In selected cases surgical management in the form of peripheral bypass surgery will help in addressing the condition. 


\section{REFERENCES}

1. Dua A, Lee CJ. Epidemiology of Peripheral Arterial Disease and Critical Limb Ischemia. Tech Vasc Interv Radiol. 2016;19: 91-95.

2. Patel MR, Conte MS, Cutlip DE, Dib N, Geraghty P, Gray $W$, et al. Evaluation and treatment of patients with lower extremity peripheral artery disease: consensus definitions from Peripheral Academic Research Consortium (PARC). J Am Coll Cardiol. 2015;65: 931-941.

3. Mueller T, Hinterreiter F, Poelz W, Haltmayer M, Dieplinger B. Predictors of 10-year mortality are different in diabetic and non-diabetic patients with chronic lower extremity peripheral arterial disease. Atherosclerosis. 2016. pp. e147-e148. doi:10.1016/j.atherosclerosis.2016.07.726

4. Gavorník P, Dukát A, Gašpar L', Gubo G, Bežillová NA, Kováčová $M$, et al. Management of diabetic patients with lower extremity peripheral arterial disease. Vnitr Lek. 2019;65: 326.

5. Halliday A, Bax JJ. The 2017 ESC Guidelines on the Diagnosis and Treatment of Peripheral Arterial Diseases, in Collaboration With the European Society for Vascular Surgery (ESVS). Eur J Vasc Endovasc Surg. 2018;55: 301302.

6. Rutherford RB. Clinical Staging of Acute Limb Ischemia as the Basis for Choice of Revascularization Method: When and How to Intervene. Seminars in Vascular Surgery. 2009. pp. 5-9. doi:10.1053/j.semvascsurg.2008.12.003

7. Diaconu' ['camelia C., Horodinschi' 'ruxandra-Nicoleta, Belciu'] 'diana. Clinical presentation of lower extremity arterial disease (LEAD). [cited 21 Aug 2020]. Available: https://www.escardio.org/Journals/E-Journal-ofCardiology-Practice/Volume-16/Clinical-presentation-oflower-extremity-arterial-disease-LEAD

8. Darling JD, McCallum JC, Soden PA, Guzman RJ, Wyers MC, Hamdan AD, et al. Predictive ability of the Society for Vascular Surgery Wound, Ischemia, and foot Infection (WIfI) classification system after first-time lower extremity revascularizations. J Vasc Surg. 2017;65: 695-704.

9. Nirala N, Periyasamy R, Kumar A. Noninvasive Diagnostic Methods for Better Screening of Peripheral Arterial Disease. Ann Vasc Surg. 2018;52: 263-272.

10. Rice TW, Lumsden AB. Optimal medical management of peripheral arterial disease. Vasc Endovascular Surg. 2006;40: 312-327.

11. Patel AY, Gurm HS. Medical Management of Lower Extremity Peripheral Artery Disease. Practical Approach to Peripheral Arterial Chronic Total Occlusions. 2017. pp. 1-8. doi:10.1007/978-981-10-3053-6_1
12. Anand SS, Caron F, Eikelboom JW, Bosch J, Dyal L, Aboyans $\mathrm{V}$, et al. Major Adverse Limb Events and Mortality in Patients With Peripheral Artery Disease: The COMPASS Trial. J Am Coll Cardiol. 2018;71: 2306-2315.

13. Ghimire M, Pahari B, Das G, Sharma SK, Das GC. Prevalence of Peripheral Arterial Disease (PAD) in End Stage Renal Disease (ESRD) Patients on Hemodialysis: a study from central Nepal. Kathmandu Univ Med J . 2014;12: 181184.

14. Sodhi HS, Shrestha SK, Rauniyar R, Rawat B. Prevalence of peripheral arterial disease by ankle-brachial index and its correlation with carotid intimal thickness and coronary risk factors in Nepalese population over the age of forty years. Kathmandu Univ Med J . 2007;5: 12-15.

15. Krishnan MN, Geevar Z, Mohanan PP, Venugopal K, Devika $\mathrm{S}$. Prevalence of peripheral artery disease and risk factors in the elderly: A community based cross-sectional study from northern Kerala, India. Indian Heart Journal. 2018. pp. 808-815. doi:10.1016/j.ihj.2017.11.001

16. Stoffers HEJH, Henri E J, Kester ADM, Kaiser V, Paula E L, André Knottnerus J. Diagnostic Value of Signs and Symptoms Associated with Peripheral Arterial Occlusive Disease Seen in General Practice. Medical Decision Making. 1997. pp. 61-70. doi:10.1177/0272989x9701700107

17. Kithcart AP, Beckman JA. ACC/AHA Versus ESC Guidelines for Diagnosis and Management of Peripheral Artery Disease: JACC Guideline Comparison. J Am Coll Cardiol. 2018;72: 2789-2801.

18. American Diabetes Association. 10. Microvascular Complications and Foot Care: Diabetes Care. 2018;41: S105-S118.

19. Hennion DR, Siano KA. Diagnosis and treatment of peripheral arterial disease. Am Fam Physician. 2013;88: 306-310.

20. Ramanathan A, Conaghan PJ, Jenkinson AD, Bishop CR. Comparison of ankle-brachial pressure index measurements using an automated oscillometric device with the standard Doppler ultrasound technique. ANZ J Surg. 2003;73: 105-108.

21. Stegall HF, Kardon MB, Kemmerer WT. Indirect measurment of arterial blood pressure by Doppler ultrasonic sphygmomanometry. J Appl Physiol. 1968;25: 793-798.

22. Gupta $\mathrm{P}$, Lyons $\mathrm{S}$, Hedgire $\mathrm{S}$. Ultrasound imaging of the arterial system. Cardiovasc Diagn Ther. 2019;9: S2-S13. 
23. Kawarada O, Hozawa K, Zen K, Huang H-L, Kim SH, Choi D, et al. Peak systolic velocity ratio derived from quantitative vessel analysis for restenosis after femoropopliteal intervention: a multidisciplinary review from Endovascular Asia. Cardiovasc Interv Ther. 2020;35: 52-61.

24. Selvin E, Erlinger TP. Prevalence of and risk factors for peripheral arterial disease in the United States: results from the National Health and Nutrition Examination Survey, 1999-2000. Circulation. 2004;110: 738-743.

25. Sebastianski M, Makowsky MJ, Dorgan M, Tsuyuki RT. Paradoxically lower prevalence of peripheral arterial disease in South Asians: a systematic review and metaanalysis. Heart. 2014;100: 100-105.

26. Vouyouka AG, Egorova NN, Salloum A, Kleinman L, Marin $M$, Faries $P L$, et al. Lessons learned from the analysis of gender effect on risk factors and procedural outcomes of lower extremity arterial disease. J Vasc Surg. 2010;52: 1196-1202.

27. Firnhaber JM, Powell CS. Lower Extremity Peripheral Artery Disease: Diagnosis and Treatment. Am Fam Physician. 2019;99: 362-369.

28. Fowkes FGR, Housley E, Cawood EHH, Macintyre CCA, Ruckley CV, Prescott RJ. Edinburgh Artery Study: Prevalence of Asymptomatic and Symptomatic Peripheral Arterial Disease in the General Population. International Journal of Epidemiology. 1991. pp. 384-392. doi:10.1093/ ije/20.2.384.

29. Criqui MH, Aboyans V. Epidemiology of Peripheral Artery Disease. Circulation Research. 2015. pp. 1509-1526. doi:10.1161/circresaha.116.303849.

30. Conte SM, Vale PR. Peripheral Arterial Disease. Heart Lung Circ. 2018;27: 427-432.

31. Hirsh AT, Criqui MH, Treat-Jacobson D. Peripheral arterial disease detection, awareness, and treatment in primary care. ACC Current Journal Review. 2002. p. 30. doi:10.1016/ s1062-1458(01)00559-1

32. Weragoda J, Seneviratne R, Weerasinghe MC, Wijeyaratne SM. ABPI against Colour Duplex Scan: A Screening Tool for Detection of Peripheral Arterial Disease in Low Resource Setting Approach to Validation. Int J Vasc Med. 2016;2016: 1390475.
33. Hirsch AT, Haskal ZJ, Hertzer NR, Bakal CW, Creager MA, Halperin JL, et al. ACC/AHA 2005 Practice Guidelines for the management of patients with peripheral arterial disease (lower extremity, renal, mesenteric, and abdominal aortic): a collaborative report, TransAtlantic Inter-Society Consensus; and Vascular Disease Foundation. Circulation. 2006;113: e463-654.

34. Hur KY, Jun JE, Choi YJ, Lee YH, Kim DJ, Park SW, et al. Color Doppler Ultrasonography Is a Useful Tool for Diagnosis of Peripheral Artery Disease in Type 2 Diabetes Mellitus Patients with Ankle-Brachial Index 0.91 to 1.40. Diabetes Metab J. 2018;42: 63-73.

35. Alexandrov AV, Brodie DS, McLean A, Hamilton P, Murphy J, Burns PN. Correlation of peak systolic velocity and angiographic measurement of carotid stenosis revisited. Stroke. 1997;28: 339-342.

36. Ranke C, Creutzig A, Alexander K. Duplex scanning of the peripheral arteries: Correlation of the peak velocity ratio with angiographic diameter reduction. Ultrasound Med Biol. 1992;18: 433-440.

37. Franz RW, Jump MA, Spalding MC, Jenkins JJ 2nd. Accuracy of duplex ultrasonography in estimation of severity of peripheralvascular disease. Int JAngiol. 2013;22:155-158.

38. Spentzouris G, Labropoulos N. The evaluation of lowerextremity ulcers. Semin Intervent Radiol. 2009;26: 286295.

39. Azuma N, Koya A, Uchida D, Saito Y, Uchida H. Ulcer Healing After Peripheral Intervention. Circ J. 2014;78: 1791-1800.

40. Kobayashi N, Hirano K, Nakano M, Muramatsu T, Tsukahara $\mathrm{R}$, Ito $\mathrm{Y}$, et al. Wound healing and wound location in critical limb ischemia following endovascular treatment. Circ J. 2014;78: 1746-1753.

41. Baubeta Fridh $E$, Andersson $M$, Thuresson $M$, Sigvant $B$, Kragsterman B, Johansson $S$, et al. Amputation Rates, Mortality, and Pre-operative Comorbidities in Patients Revascularised for Intermittent Claudication or Critical Limb Ischaemia: A Population Based Study. Eur J Vasc Endovasc Surg. 2017;54: 480-486.

42. Duff S, Mafilios MS, Bhounsule P, Hasegawa JT. The burden of critical limb ischemia: a review of recent literature. Vasc Health Risk Manag. 2019;15: 187-208. 